\title{
Complete genome sequence of Staphylococcus aureus, strain ILRI_Eymole1/1, isolated from a Kenyan dromedary camel
}

\author{
Saima Zubair ${ }^{1}$, Anne Fischer ${ }^{2,3}$, Anne Liljander², Jochen Meens ${ }^{4}$, Jan Hegermann ${ }^{5,6,7}$, Hadrien Gourlé1, \\ Richard P. Bishop², Ina Roebbelen², Mario Younan ${ }^{8}$, Mudassir Imran Mustafa ${ }^{9}$, Mamoona Mushtaq ${ }^{1}$, \\ Erik Bongcam-Rudloff ${ }^{*}$ and Joerg Jores ${ }^{2}$
}

\begin{abstract}
We report the genome of a Staphylococcus aureus strain (ILRI_Eymole1/1) isolated from a nasal swab of a dromedary camel (Camelus dromedarius) in North Kenya. The complete genome sequence of this strain consists of a circular chromosome of 2,874,302 bp with a GC-content of $32.88 \%$. In silico annotation predicted 2755 protein-encoding genes and 76 non-coding genes. This isolate belongs to MLST sequence type 30 (ST30). Phylogenetic analysis based on a subset of 283 core genes revealed that it falls within the human clonal complex 30 (CC30) S. aureus isolate cluster but is genetically distinct. About $79 \%$ of the protein encoding genes are part of the CC30 core genome (genes common to all CC30 S. aureus isolates), $18 \%$ were within the variable genome (shared among multiple but not all isolates) and $\sim 3 \%$ were found only in the genome of the camel isolate. Among the 85 isolate-specific genes, 79 were located within putative phages and pathogenicity islands. Protein encoding genes associated with bacterial adhesion, and secretory proteins that are essential components of the type VII secretion system were also identified. The complete genome sequence of S. aureus strain ILRI_Eymole1/1 has been deposited in the European Nucleotide Archive under the accession no LN626917.1.
\end{abstract}

Keywords: Staphylococcus aureus, ST30, Camel, Pathogenicity islands, Core genome

\section{Introduction}

S. aureus is a bacterial species which has been isolated from diverse hosts including humans, other mammals and birds $[1,2]$. In humans, it is persistently present in the nares of approximately $20 \%$ of all individuals and intermittently carried by nearly $30 \%$ individuals [3]. S. aureus has been reported to be a common cause of wound infections, pneumonia and bacteraemia in humans in Kenya $[4,5]$. In small and large ruminants and pseudo ruminants such as dromedary camels (Camelus dromedaries), S. aureus causes mastitis and therefore negatively impacts the productivity of the dairy industry worldwide $[6,7]$.

\footnotetext{
* Correspondence: erik.bongcam@slu.se

'Department of Animal Breeding and Genetics, SLU Global Bioinformatics Centre, Swedish University of Agricultural Sciences, SE-75007 Uppsala, Sweden

Full list of author information is available at the end of the article
}

Zoonotic transmission of $S$. aureus has also been reported $[8,9]$. In arid and semi arid regions of the Greater Horn of Africa, camels represent an important and valuable livestock species that provides a significant percentage of the population with animal protein, particularly from milk [10]. Moreover, camel milk is often consumed raw without proper heat-treatment, which increases the risk of acquiring infections with zoonotic pathogens [11, 12].

Currently our knowledge of bacterial pathogens in camels is rather limited [13]. S. aureus has been reported to cause infections of the skin, udder, eyes and joints [14-17] in camels. In North Kenya between 1999 and 2004, the prevalence of $S$. aureus in camels has been reported as $54 \%$ in closed skin abscesses, $36 \%$ in open skin abscesses, $39 \%$ in skin necrosis and $31 \%$ in lymph node abscesses [15]. A recent survey reports the prevalence of 
intramammary infections (IMI) associated with $S$. aureus as $11 \%$ in lactating camels in Kenya [16]. A study has also reported genotype data and identified 'candidate' virulence factors of $S$. aureus strains in Middle Eastern camels [14]. Here we present the complete genome sequence, annotation and comparative analysis of the $S$. aureus ST30 strain ILRI_Eymole1/1 isolated from a nasal swab of a dromedary camel in Kenya.

\section{Organism information}

\section{Classification and features}

The $S$. aureus strain ILRI_Eymole1/1 was isolated in Kenya in 2004 from a nasal swab of a camel. It was identified as a member of the Staphylococcus aureus species on the basis of standard microbiological procedures [18] combined with a species-specific PCR [19]. S. aureus is a Gram-positive, coccus shaped, non-motile, nonspore forming and facultative anaerobic bacterium. S. aureus were grown on agar. Agar pieces were cut out and fixed in $150 \mathrm{mM}$ HEPES, pH 7.35, containing $1.5 \%$ formaldehyde and $1.5 \%$ glutaraldehyde for $30 \mathrm{~min}$ at room temperature and at $4{ }^{\circ} \mathrm{C}$ over night. After dehydration in acetone and critical point drying, cells were gold sputtered and observed in a Philips SEM 505. Images were acquired using $10 \mathrm{kV}$ at $10.000 \times / 20 \mathrm{~nm}$ spot size or $40.00 \times / 10 \mathrm{~nm}$ spot size. The bacterial cells are 0.5 to $1.0 \mathrm{~mm}$ in diameter, and occurs either singly or in the form of pairs or clusters (Fig. 1). The culture produces smooth, circular, glistening colonies of diameter $>5 \mathrm{~mm}$. It produces a grey pigment. The general features of $S$. aureus strain Eymole1/1 are presented in Table 1 and Additional file 1: Table S1. The optimal growth temperature range is $37-42{ }^{\circ} \mathrm{C}$. Tolerance to $\mathrm{NaCl}$ was tested in liquid medium, $\mathrm{LB}$ with $\mathrm{NaCl}$ concentrations between 0 and $4 \mathrm{M} \mathrm{NaCl}$. Cells were grown overnight at $37^{\circ} \mathrm{C}$.

Carbohydrate utilization was tested using ID 32 STAPH, a standardized system for the identification of the genera Staphylococcus, Micrococcus etc. (bioMérieux, Inc, Box 15969,Durham, NC 27704-0969 / USA). These tests showed positive results for glucose, fructose, mannose, maltose, lactose, trehalose, sucrose and turanose.

The sequence type of the $S$. aureus isolate was determined using a previously described MLST dataset [20]. ILRI_Eymole1/1 belongs to ST30 MLST group. A BLASTn search [21] of all five copies of $16 \mathrm{~S}$ rRNA sequence of ILRI_Eymole1/1 using default parameters revealed 99-100 \% identity (with 98-100 \% coverage) with all available $S$. aureus genomes in the database. The phylogenetic relationship was established using the $16 \mathrm{~S}$ rRNA sequences of the type strains defining the genus Staphylococcus (accession numbers are provided in Additional file 2: Table S2). In addition, the $16 \mathrm{~S}$ rRNA sequences of $9 \mathrm{~S}$. aureus isolates (NC_021554, NC_017333, NC_017349, NC_022113, NC_002952, NC_017342, NC_ 002758, NC_002745, NC_020529) were extracted from the genome sequences, and a neighbor joining phylogenetic tree was constructed with MEGA v.6.06 (Fig. 2). The tree illustrates the close relationship of $S$. aureus ILRI_Eymole1/1 with $S$. aureus isolates from ST 30, 36, 5, 45 and the $S$. aureus type strain L36472 (Fig. 2). The position relative to other species within the genus Staphylococcus is also illustrated. Bacillus subtilis type strain DSM10 was used as an outgroup for the genus Staphylococcus.

\section{Genome sequencing information}

\section{Genome project history}

Twenty three strains of S. aureus have been isolated from healthy and diseased camels in East Africa using standard methods (1). The strains were isolated using primary cultivation on Columbia blood agar plates (Oxoid, UK) and were sub-cultured on mannitol-salt agar plates (Oxoid, UK). Afterwards the strains were subjected to multi locus sequence typing (2). Four strains belonged to sequence type 30, previously characterized in humans. The other isolates had novel sequence types that were likely to be camel specific. We selected the strain ILRIEymole1/1 for subsequent analysis since we wanted to elucidate the relationship of $S$. aureus isolates from camels
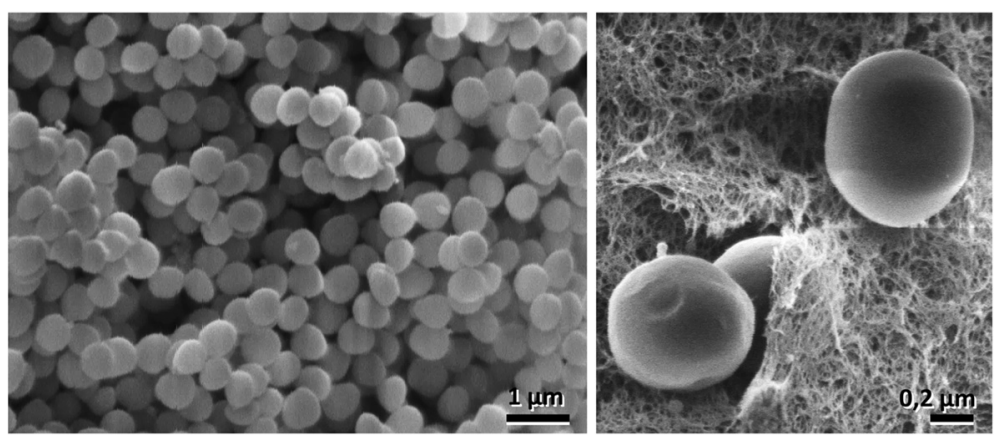

Fig. 1 Scanning electron microscopy of ILRI Eymole 1/1 S. aureus grown on agar. Left: overview of cells grown in a colony; right: single cells in higher magnification 
Table 1 Classification and general features of Staphylococcus aureus ILRI_Eymole1/1

\begin{tabular}{|c|c|c|c|}
\hline MIGS ID & Property & Term & Evidence code $^{\mathrm{a}}$ \\
\hline & Classification & Domain Bacteria & TAS [49] \\
\hline & & Phylum Firmicutes & $\operatorname{TAS}[50,51]$ \\
\hline & & Class Bacilli & $\operatorname{TAS}[52,53]$ \\
\hline & & Order Bacillales & TAS [54-57] \\
\hline & & Family Staphylococcaceae & $\operatorname{TAS}[53,58]$ \\
\hline & & Genus Staphylococcus & IDA \\
\hline & & Species Staphylococcus aureus & IDA \\
\hline & & Strain: ILRI_Eymole1/1 (Accession \# LN626917.1) & \\
\hline & Gram stain & Positive & IDA \\
\hline & Cell shape & Grape-like coccus & IDA \\
\hline & Motility & Nonmotile & IDA \\
\hline & Sporulation & Nonspore-forming & IDA \\
\hline & Temperature range & $15-42{ }^{\circ} \mathrm{C}$ & IDA \\
\hline & Optimum temperature & $37^{\circ} \mathrm{C}$ & IDA \\
\hline & $\mathrm{pH}$ & $4.5-9.5$ & IDA \\
\hline & Optimum pH & 7 & \\
\hline & Carbon Source & $\begin{array}{l}\text { Glucose, fructose, mannose, maltose, lactose, } \\
\text { trehalose, sucrose, turanose }\end{array}$ & IDA \\
\hline MIGS-6 & Habitat & Nasopharyngeal microflora & \\
\hline MIGS-6.3 & Salinity & 1 to $2.5 \mathrm{M} \mathrm{NaCl}$ & IDA \\
\hline MIGS-22 & Oxygen requirement & Facultative anaerobe & $\operatorname{TAS}[59,61]$ \\
\hline MIGS-15 & Biotic relationship & Free living & \\
\hline MIGS-14 & Pathogenicity & - & \\
\hline MIGS-4 & Geographic location & Kenya & \\
\hline MIGS-5 & Sample collection & 01 February 2004 & \\
\hline MIGS-4.1 & Latitude & 3.916667 & \\
\hline MIGS-4.2 & Longitude & 41.833333 & \\
\hline MIGS-4.3 & Depth & - & \\
\hline MIGS-4.4 & Altitude & 220 & \\
\hline
\end{tabular}

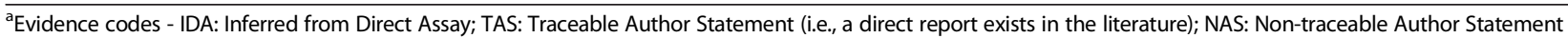
(i.e., not directly observed for the living, isolated sample, but based on a generally accepted property for the species, or anecdotal evidence). These evidence codes are from the Gene Ontology project [62]

and humans in order to project a zoonotic potential. S. aureus ILRI_Eymole1/1 was isolated from a nasal swab taken (transport Amies swab w/o charcoal, Copan, Italy) from a dromedary camel calf with rhinitis in Kenya in 2004.

\section{Growth conditions and genomic DNA preparation}

The strain was grown in $10 \mathrm{ml}$ liquid Brain heart medium (Carl Roth, Germany) at $37{ }^{\circ} \mathrm{C}$ and $200 \mathrm{rpm}$ overnight. The strain was grown in $10 \mathrm{ml}$ liquid Brain heart medium (Carl Roth, Germany) at $37{ }^{\circ} \mathrm{C}$ and $200 \mathrm{rpm}$ overnight. The bacterial cells were pelleted using centrifugation at $5000 \times \mathrm{g}$ for $20 \mathrm{~min}$. The supernatant was discarded and cells were subjected to genomic DNA isolation using the PureLink $^{\text {TM }}$ Genomic DNA Mini Kit (Invitrogen, USA) according to vendor's instructions. The DNA was quantified using the Qubit ${ }^{\bullet}$ 3.0 Fluorometer (Thermo Scientific, Kenya) and the Qubit $^{\circ}$ dsDNA BR Assay Kit (Thermo Scientific, Kenya). The DNA concentration was $84.6 \mathrm{ng} /$ ul, the $260 / 280$ and $260 / 230$ ratios were 1.49 and 0.56 , respectively. To remove impurities, the DNA was further cleaned using a ratio of 1.6 AMPure beads (ref).

\section{Genome sequencing and assembly}

Genome sequencing of $S$. aureus ILRI_Eymole1/1 was performed using the Illumina Genome Analyzer GAIIx platform. A 300 bp paired-end library with an average insert size of $550 \mathrm{bp}$ was sequenced. The software MIRA v 4.0 [22] was used to assemble the S. aureus ILRI_Eymole1/ 1 genome, using as the input 1,154,246 Illumina pairedend reads. The de novo genome assembly generated a total 


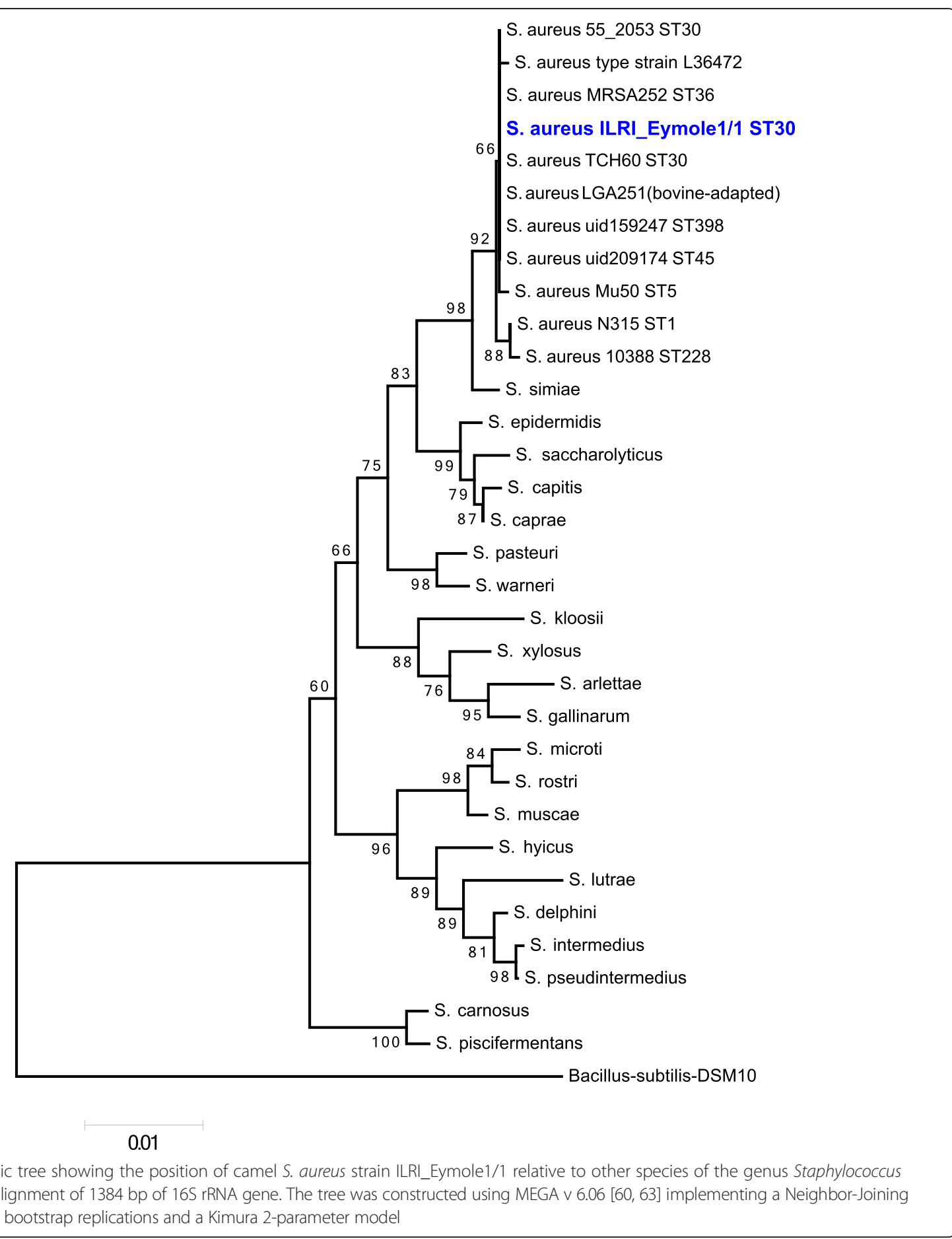

of 118 contigs with average coverage of $109 \times$ and average quality of 83 (Table 2). The whole genome alignment tools Mauve [23] and MUMmer v 3.2.2 [24] were used to order contigs of length greater than $1000 \mathrm{bp}$ (69 contigs) against a reference genome sequence MRSA252/NC_002952 [25]. A complete genome sequence was obtained by joining the ordered contigs on the basis of their overlaps. The assembly output ACE file was viewed and analyzed in Tablet viewer version 1.13.05.17 [26].

\section{Genome annotation}

The complete genome sequence of $S$. aureus ILRI_Eymole1/1 was annotated using RAST [27]. Ribosomal RNA genes were identified using RNAmmer server v 1.2 
Table 2 Project information

\begin{tabular}{|c|c|c|}
\hline MIGS ID & Property & Term \\
\hline MIGS-31 & Finishing quality & Finished \\
\hline MIGS-28 & Libraries used & $\begin{array}{l}\text { Illumina Paired End; } \\
\text { Average read length } 300 \text { bp; } \\
\text { Average insert size } 550 \text { bp. }\end{array}$ \\
\hline MIGS-29 & Sequencing platforms & Illumina GA-II \\
\hline MIGS-31.2 & Fold coverage & $109 \times$ \\
\hline MIGS-30 & Assemblers & MIRA 4.0 \\
\hline \multirow[t]{6}{*}{ MIGS-32 } & Gene calling method & RAST server, Basys \\
\hline & Locus Tag & - \\
\hline & Genbank ID & LN626917.1 \\
\hline & Genbank Date of Release & October 31, 2014 \\
\hline & GOLD ID & Gp0109422 \\
\hline & BIOPROJECT & PRJEB6577 \\
\hline \multirow[t]{2}{*}{ MIGS-13 } & Source Material Identifier & ILRI_Azizi_biobank \\
\hline & Project relevance & Bacterial pathogen in camels \\
\hline
\end{tabular}

[28], and the tRNA genes were predicted using tRNA scan-SE v 1.21 [29]. The COG genes and associated functional categories information were downloaded from the COG database [30]. The COG categories were assigned to the ILRI_Eymole1/1 genome annotation using blastp $\mathrm{v}$ 2.2.28 [31] against the COG genes collection/ myva. Genes with more than $40 \%$ amino acid identity and with e-values of less than 0.00005 were classified as putative homologues of genes within the COG database, and functional categories were assigned. Signal peptides were predicted using the SignalP v 4.1 server [32], and the transmembrane helices/ membrane spanning domains were identified using TopPred2 [33]. Phage-like sequences were predicted using PHAST [34].

\section{Genome properties}

The S. aureus ILRI_Eymole1/1 genome is a circular chromosome of 2,874,302 bp with a GC-content of $32.88 \%$. A total of 2831 genes were predicted comprising 2755 protein encoding genes, 60 tRNA genes and 16 rRNA genes (Table 3, Fig. 3). Five copies of both $16 \mathrm{~S}$ and 23S rRNA genes and six copies of 5S rRNA genes were identified. Among the predicted protein encoding genes, $652(23.66 \%)$ were hypothetical proteins. A total of 162 genes ( $5.88 \%$ ) were predicted to encode proteins with secretory signal peptides (potentially targeted to the secretory pathway) and 1040 (37.75\%) were genes encoding proteins with transmembrane helices or membrane spanning proteins. A total of 2054 (74.56 \%) predicted genes were assigned to COG functional categories, while $701(25.44 \%)$ were not present within the COG collection (Table 4).
Table 3 Nucleotide content and gene count levels of the

\begin{tabular}{lrc} 
genome & \multicolumn{1}{l}{ Value } & \% of total \\
\hline Attribute & $2,874,302$ & 100.00 \\
\hline Genome Size (bp) & $2,404,314$ & 83.65 \\
DNA coding & 945,066 & 32.88 \\
DNA G + C (bp) & 2831 & 100.00 \\
Total genes & 2755 & 97.32 \\
Protein-coding genes & 76 & 2.68 \\
RNA genes & 0 & 0.00 \\
Pseudo genes & $n / a$ & $n / a$ \\
Genes in internal clusters & 2170 & 76.65 \\
Genes with function prediction & 2054 & 74.56 \\
Genes assigned to COGs & 1688 & 59.63 \\
Genes with Pfam domains & 162 & 5.88 \\
Genes with signal peptides & 1046 & 37.97 \\
Genes with transmembrane helices & 0 & 0.00 \\
\hline CRISPR repeats &
\end{tabular}

${ }^{a}$ The total is based on either the size of the genome in base pairs or the total number of protein coding genes in the annotated genome

\section{Insights from the genome sequence}

We performed a comparative analysis of the camel $S$. aureus ILRI Eymole1/1 isolate of sequence type 30 with 16 previously sequenced ST30 S. aureus isolates, two ST36 methicillin resistance Staphylococcus aureus isolates MRSA252, EMRSA16 and one ST431 S. aureus isolate M809, which together belong to the clonal complex 30 (CC30). ST36 and ST431 are single locus MLST variants of ST30. Previously sequenced $S$. aureus complete genome sequences were downloaded from the NCBI FTP site [35] (accession numbers are provided in Additional file 3: Table S3), and CC30 isolates were selected by analyzing their house keeping genes using the $S$. aureus MLST database [20]. The collection of draft S. aureus CC30 genomes was derived from previous studies [36, 37].

\section{Core genome analysis and COG classification}

All 20 S. aureus CC30 genomes were annotated using the RAST server, and amino acid sequences of protein encoding genes from all CC30 genomes were used for the core genome analysis. Blastp searching of protein sequences of all CC30 isolates was carried out using local blastp $\mathrm{v}$ 2.2.28 [31]. The genes matching in all CC30 genomes with $>=80 \%$ identity, e-value $<0.00005$, and alignment length $>=50 \%$ were classified as core genes using custom scripts (Additional file 4: Supplementary material S4). The core genes were further analyzed for their COG functional classification using a matching criterion of $>=40 \%$ identity and an e-value $<0.00005$. Among 2163 core genes, 1810 (83.68 \%) were present in COG database, whereas 353 (16.32\%) were not present 


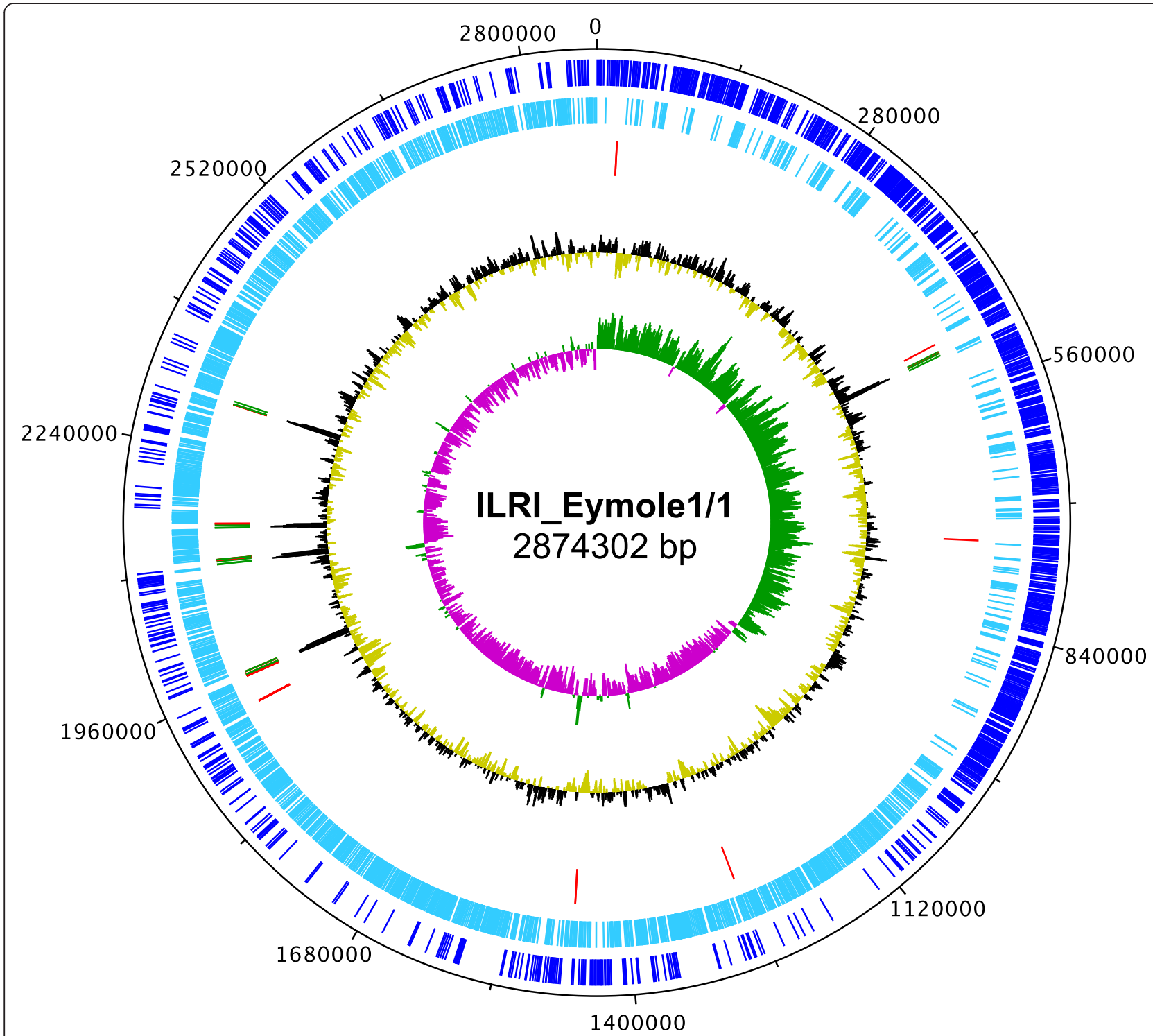

Fig. 3 Circular map of the S. aureus ILRI_Eymole1/1 genome. From outer to inner circle; 1) Protein encoding genes in forward orientation are shown in dark blue, 2) Protein encoding genes in reverse orientation are shown in light blue, 3) Ribosomal RNAs are depicted in green while tRNAs are in red, 4) G + C-content plot and 5) GC-skew graph. The Graph was generated using DNAPlotter [64]

in COG database. The functional classification of these genes is shown in Fig. 4.

S. aureus ILRI_Eymole1/1 variable genes (shared with some of the CC30 S. aureus genomes), and isolatespecific genes were also identified. We identified 2163 core genes (78.51\% of the total protein encoding genes), $507(18.40 \%)$ variable protein-encoding genes and 85 (3.09\%) isolate-specific genes.

\section{Bacterial adhesins}

The colonization and adhesion of $S$. aureus to the nasal epithelial cells is thought to be mediated by surface proteins $\mathrm{ClfB}$, IsdA and the serine-aspartic acid repeat proteins $\mathrm{SdrC}$ and SdrE. A published study demonstrated that a mutant lacking these four proteins did not exhibit the adherence phenotype [38]. S. aureus ILRI_Eymole1/1 possesses genes encoding fibrinogen-binding protein ClfB (CEH27447), adhesin proteins SdrC (CEH25318) and SdrE (CEH25319), in common with a subset of the CC30 S. aureus genomes. A gene encoding Heme/ Iron regulated surface protein IsdA (CEH26009) was present among the core protein repertoire of ILRI_Eymole1/1 isolate, and is known to be important for $S$. aureus infection of human skin, through mediating resistance to skin innate defense mechanisms [39].

S. aureus ILRI_Eymole1/1 possessed genes encoding many fibrinogen-binding proteins, including clumping factor/ fibrinogen binding protein ClfA, (CEH26520: variable 
Table 4 Number of genes associated with the 25 general COG functional categories

\begin{tabular}{|c|c|c|c|}
\hline Code & Value & $\%$ of total ${ }^{a}$ & Description \\
\hline J & 145 & 5.26 & Translation \\
\hline A & 0 & 0.00 & RNA processing and modification \\
\hline K & 120 & 4.36 & Transcription \\
\hline L & 148 & 5.37 & Replication, recombination and repair \\
\hline B & 0 & 0.00 & Chromatin structure and dynamics \\
\hline $\mathrm{D}$ & 24 & 0.87 & Cell cycle control, mitosis and meiosis \\
\hline Y & 0 & 0.00 & Nuclear structure \\
\hline V & 45 & 1.63 & Defense mechanisms \\
\hline $\mathrm{T}$ & 35 & 1.27 & Signal transduction mechanisms \\
\hline M & 90 & 3.27 & Cell wall/membrane biogenesis \\
\hline N & 1 & 0.04 & Cell motility \\
\hline Z & 0 & 0.00 & Cytoskeleton \\
\hline W & 0 & 0.00 & Extracellular structures \\
\hline$U$ & 20 & 0.73 & Intracellular trafficking and secretion \\
\hline O & 61 & 2.21 & $\begin{array}{l}\text { Posttranslational modification, } \\
\text { protein turnover, chaperones }\end{array}$ \\
\hline C & 91 & 3.30 & Energy production and conversion \\
\hline G & 106 & 3.85 & Carbohydrate transport and metabolism \\
\hline$E$ & 174 & 6.32 & Amino acid transport and metabolism \\
\hline $\mathrm{F}$ & 64 & 2.32 & Nucleotide transport and metabolism \\
\hline $\mathrm{H}$ & 77 & 2.80 & Coenzyme transport and metabolism \\
\hline | & 50 & 1.82 & Lipid transport and metabolism \\
\hline$P$ & 124 & 4.50 & Inorganic ion transport and metabolism \\
\hline Q & 23 & 0.84 & $\begin{array}{l}\text { Secondary metabolites biosynthesis, } \\
\text { transport and catabolism }\end{array}$ \\
\hline $\mathrm{R}$ & 228 & 8.28 & General function prediction only \\
\hline S & 220 & 7.99 & Function unknown \\
\hline- & 208 & 7.55 & Other COG categories \\
\hline- & 701 & 25.44 & Not in COGs \\
\hline
\end{tabular}

${ }^{\mathrm{a}}$ The total is based on the total number of protein coding genes in the annotated genome

gene), fibronectin/ fibrinogen binding protein FnBP (CEH25930: core gene), extracellular fibrinogen-binding protein Efb (CEH25981: core gene), fibronectin binding protein FnbB (CEH27312: variable gene), fibronectin binding protein FnbA (CEH27314: variable gene), and clumping factor $\mathrm{ClfB}$, fibrinogen binding protein (CEH27447: variable gene). These FnBPs bind the host fibronectin receptor $\beta 1$-integrins to promote $S$. aureus invasion of various mammalian cells including epithelial cells, endothelial cells and fibroblasts. These cells do not require specific co-receptors for S. aureus [40].

A gene encoding an extracellular adherence protein of broad specificity Eap/Map (CEH26760: core gene) was also identified in the camel $S$. aureus isolate. This protein has been reported to be involved in $S$. aureus internalization into the host cells. Eap is known to be responsible for agglutination of bacterial cells by rebinding to the surface of S. aureus. It shows dual affinity for the cell surface plasma proteins as well as the bacterial surface. Eap plays a complementary role together with FnBP, in the internalization and long time persistence of $S$. aureus within eukaryotic cells. It was found to be a key component of the novel internalization pathway that works either in parallel with, or in addition to, the FnBP dependent internalization pathway [41].

\section{Sec-independent Ess secretion pathway/ Type VII secretion system, T7SS}

Many Gram-positive bacterial species, including $S$. aureus, secrete exotoxins or virulence factors across the membrane, through signal peptides or the Sec translocon. A Sec-independent translocation of these factors has also been reported in Gram-positive bacteria. Human $S$. aureus has been shown to secret the ESAT-6-like secretory proteins EsxA and EsxB. The genes encoding these proteins cluster in the genome as an operon together with several additional genes to form a secretion system, known as the type 7 secretion system (T7SS) that is involved in bacterial pathogenicity [42, 43]. The $S$. aureus isolate ILRI_Eymole1/1 possessed genes encoding proteins related to T7SS; which were also present in all other CC30 S. aureus genomes. These encoded the secretory antigen precursor SsaA (CEH25002), ESAT-6/Esx family secreted protein EsxA/YukE (CEH25003), putative secretion accessory protein EsaA/YueB (CEH25004), putative secretion system component EssA (CEH25005), putative secretion accessory protein EsaB/YukD (CEH25006), putative secretion system component EssB/YukC (CEH25007), and a FtsK/SpoIIIE family protein, together with putative secretion system component EssC/YukA (CEH25008).

\section{Isolate specific genes}

Out of the total 85 isolate specific genes encoded by $S$. aureus ILRI_Eymole1/1, 79 genes (92.94 \%) were clustered into six large insertions. Four insertions were putative bacteriophages comprising four complete phages with sizes of $52.5 \mathrm{~kb}, 30 \mathrm{~kb}, 60.3 \mathrm{~kb}$ and $58.8 \mathrm{~kb}$, respectively. All phage sequences possessed attL and attR integration sequences at the forward and reverse ends. Superantigen pathogenicity islands (SaPI) are mobile genetic elements in Gram-positive bacteria including S. aureus that carry genes associated with superantigens, virulence, resistance and metabolic functions; also named as $S$. aureus pathogenicity islands 'SaPI'. These are known for their strong association with temperate phages and result in high transfer frequencies [44]. Two insertions constituted complete SaPI islands (SaPIcam1 and SaPIcam2) at positions 426,323-443,273 and 758,187-774,130. These were confirmed by the identification of forward and reverse 


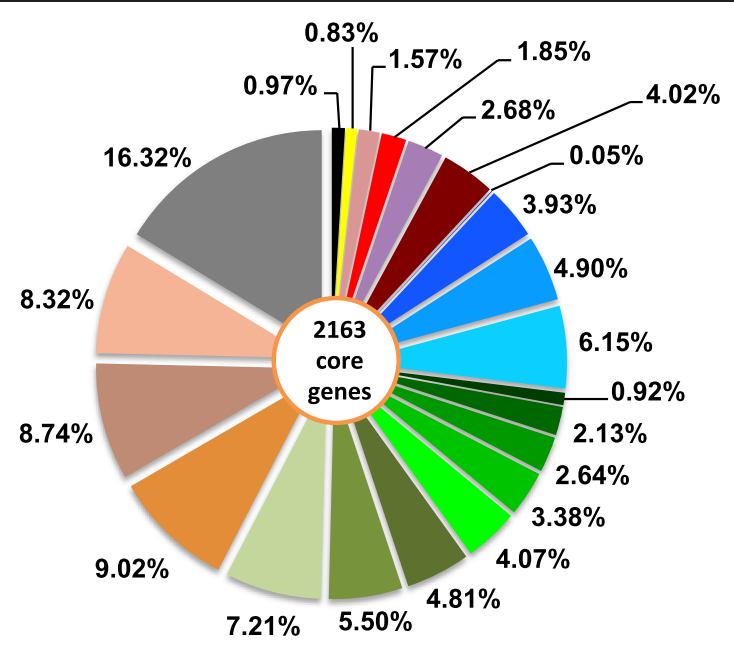

CELLULAR PROCESSES AND SIGNALING

[U,NOU,NU] Intracellular trafficking and secretion, \& Flagellum specific

[D] Cell cycle control and cell division

[T] Signal transduction mechanisms

- [V] Defense mechanisms

[O] Posttranslational modification, protein turnover, chaperones

- [M,GM] Cell wall/membrane biogenesis

INFORMATION STORAGE AND PROCESSING

- [BQ] Chromatin structure and dynamics (Histone related)

[L] Replication, recombination and repair

- [K,KT] Transcription regulators, repressors, antiterminators

[J] Translation, ribosomal structure and biogenesis

METABOLISM

- [Q] Secondary metabolites biosynthesis, transport, catabolism

[I] Lipid transport and metabolism

- [F] Nucleotide transport and metabolism

- $[\mathrm{H}]$ Coenzyme transport and metabolism

[C] Energy production and conversion

- $[\mathrm{G}, \mathrm{GT}]$ Carbohydrate transport and metabolism

[P] Inorganic ion transport and metabolism

[E] Amino acid transport and metabolism

POORLY CHARACTERIZED

[R] General function prediction only

[S] Function unknown

[Z] Other COG Categories

$-[\mathrm{XX}]$ Not in COGs

Fig. 4 COG functional classification of CC3O S. aureus core genome

sequences at the $5^{\prime}-3^{\prime}$ ends of previously characterized SaPIs, namely SaPIbov and SaPImw2 [45]. SaPIcam1 and SaPIcam2 both had integrase and terminase encoding genes at their termini. SaPIcam1 also possessed an HTHtype transcriptional regulator $\mathrm{LrpC}$ adjacent to 3 ' end. The SaPIcam2 contained a candidate superantigen tst gene (toxic shock syndrome toxin 1 TSST-1, as part of variable gene content) located adjacent to the 3' end. The 'SaPI2' island in the CC30 isolates encodes a TSST-1 gene, and these have a clonal association with CC30 nasal infective and bacteremia causing isolates [36, 46]. Among $S$. aureus CC30 isolates analyzed in this study, only ILRI_Eymole1/1, EMRSA16, A017934_97, Btn1260 and MN8 genomes contained 'SaPI2', encoding the tst gene. All other CC30 genomes possessed a 'SaPI1' island, and therefore encoded Ear, a secretory protein, at the 3 ' end. The presence of the high level of isolate specific genes $(92.94 \%)$ in these phage insertions and the SaPI islands strongly suggests the 


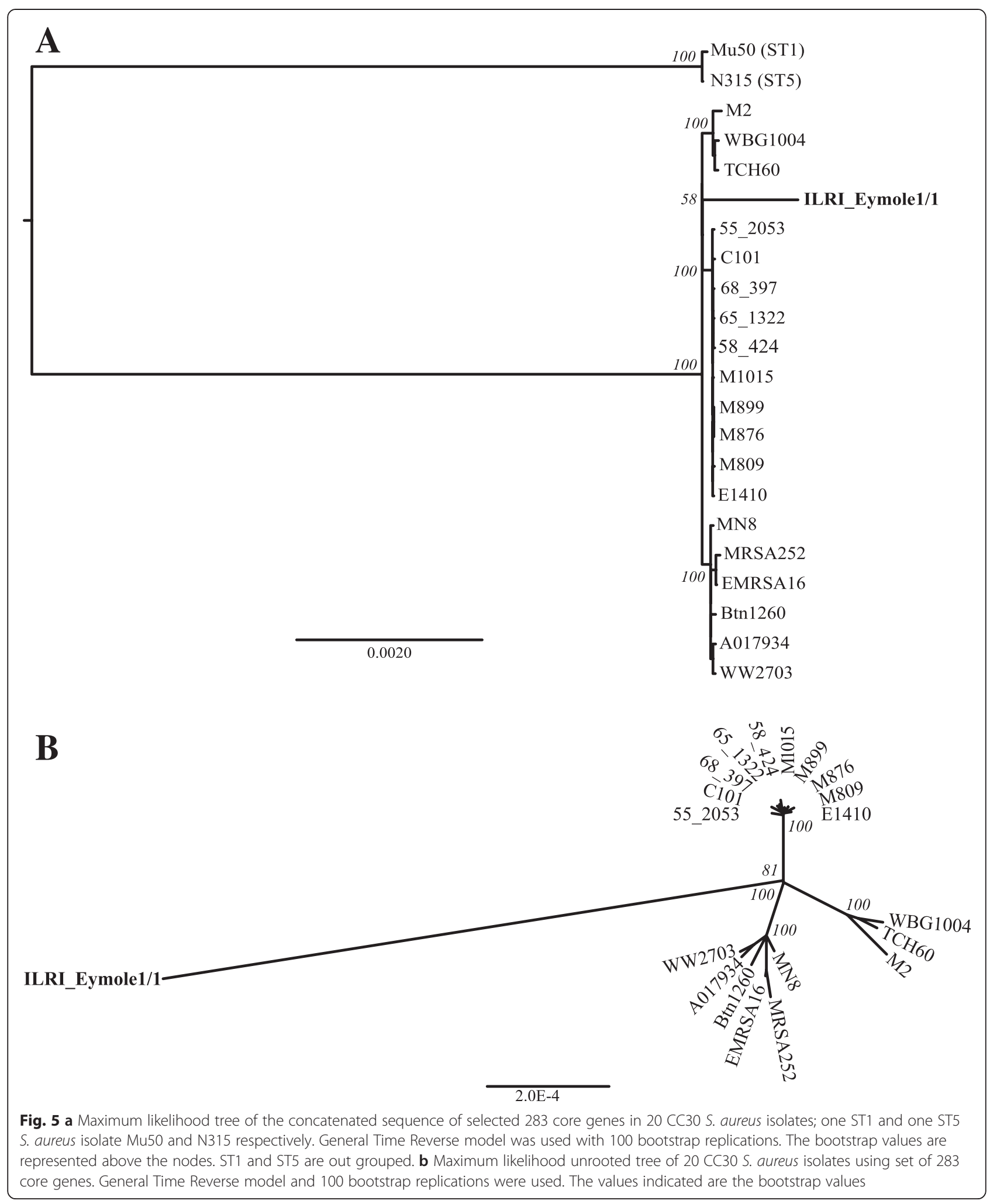


acquisition of these genes through lateral gene transfer from either phages or heterologous bacterial species harboring these insertions.

\section{Phylogeny using polymorphic set of core genes}

We determined the phylogenetic relationship among the isolates using a stringently defined set of 283 core genes that were shared among the CC30 isolates. Two S. aureus genomes from ST1 and ST5 were also included in this analysis as outgroups. The core genes were defined among these $22 \mathrm{~S}$. aureus genomes using the criteria of (identity $>=95 \%$ and $<100 \%$ ), (e-value $<0.00005$ ) and (alignment length $>=90 \%$ ). Duplicate copies of genes were filtered out, resulting in the final total of 283 core genes. Multiple sequence alignment of the concatenated sequences of these genes was performed using the Mugsy aligner [47], generating an alignment comprising 316,359 nucleotides from each isolate. We estimated a maximum likelihood phylogeny using PhyML v. 3.0 [48]. The General Time-Reversible (GTR) model was used, where the base frequencies and the relative substitution rates between them were estimated by maximizing the likelihood of the phylogeny. For estimating the tree topology both nearest neighbor interchange and subtree pruning and regrafting methods were used. One hundred bootstrap replicates were run (Fig. 5a and b).

In both rooted and unrooted trees (Fig. 5a and b), the human CC30 isolates group in three clusters, in agreement with a published study [36]. The camel S. aureus isolate ILRI_Eymole1/1 clusters in the CC30 (Fig. 5a), but is genetically distant from human CC30 S. aureus isolates (Fig. 5b).

\section{Conclusion}

Here we report the first genome of a $S$. aureus isolated from Camelus dromedarius. Our analysis shows that a high proportion of isolate-specific genes were located in putative phage insertions and SaPI islands in the camel isolate clearly distinguished it from human isolates. The analysis based on a polymorphic set of core genes clearly shows that the camel $S$.aureus isolate belongs to ST30 but this isolate has greater genetic difference when compared to human isolates. Therefore, we consider the likelihood of exchange between camel and human populations low. However, this is the complete genome of a single $S$. aureus from a camel. The analysis of additional S. aureus isolates from camels and humans living in the same area, followed by a detailed comparative and phylogenetic analysis will underpin improved understanding of host adaptation and zoonotic potential.

\section{Additional files}

Additional file 1: Table S1. Associated MIGS record. (DOC $73 \mathrm{~kb})$
Additional file 2: Table S2. The $16 \mathrm{~S}$ rRNA sequences of the type strains of genus Staphylococcus used in phylogenetic tree (Fig. 1). (DOC $47 \mathrm{~kb}$ )

Additional file 3: Table S3. General genomic features of twenty CC30 S. aureus genomes. (DOC $53 \mathrm{~kb}$ )

Additional file 4: Supplementary data. (DOCX $143 \mathrm{~kb}$ )

\section{Abbreviations}

CC30: Clonal Complex 30; MRSA: Methicillin Resistance Staphylococcus aureus; MSSA: Methicillin Susceptible/Sensitive Staphylococcus aureus.

\section{Competing interests}

The authors declare that they have no competing interests.

\section{Authors' contributions}

IR and MY collected the data; AL, JM, JH performed the laboratory work; SZ, $A F, H G, M M, M I M$ performed the analysis; EB-R and JJ designed the study; and $\mathrm{SZ}, \mathrm{AF}, \mathrm{RBP}$, JJ wrote the manuscript. All authors read and approved the final manuscript.

\section{Acknowledgements}

This work was supported by the Consultative Group of International Agricultural Research (CGIAR) program on Agriculture for Nutrition and Health. Erik Bongcam-Rudloff was partially supported by the Project ALLBIO grant number EU FP7; 289452; KBBE.2011.3.6-02. Higher Education Commission (HEC) of Pakistan supported Saima Zubair. The Centrum of International Migration (CIM) supported Anne Fischer and Anne Liljander. Support by BILS (Bioinformatics Infrastructure for Life Sciences) and UPPMAX/UPPNEX are gratefully acknowledged. We thank Gerhard Preiss for excellent maintenance and help with electron microscopes and Andrea Kofink-Germershausen and Sabine Fiedler for excellent technical assistance.

\section{Author details}

'Department of Animal Breeding and Genetics, SLU Global Bioinformatics Centre, Swedish University of Agricultural Sciences, SE-75007 Uppsala, Sweden. ${ }^{2}$ International Livestock Research Institute, PO Box 30709, Nairobi, Kenya. ${ }^{3}$ International Center for Insect Physiology and Ecology, PO Box 30722, Nairobi, Kenya. ${ }^{4}$ Department of Infectious Diseases, Institute for Microbiology, University of Veterinary Medicine Hannover, Hannover, Germany. Institute of Functional and Applied Anatomy, Hannover Medical School, Hannover, Germany. ${ }^{6}$ Biomedical Research in Endstage and Obstructive Lung Disease Hannover (BREATH), Member of the German Center for Lung Research (DZL), Hannover, Germany. ${ }^{7}$ REBIRTH Cluster of Excellence, Hannover, Germany. ${ }^{8}$ Vétérinaires sans Frontières Germany, Nairobi, Kenya. ${ }^{9}$ Department of Public Health and Caring Science, Uppsala University, 75122 Uppsala, Sweden.

Received: 5 December 2014 Accepted: 10 November 2015 Published online: 20 November 2015

\section{References}

1. Sung JM-L, Lloyd DH, Lindsay JA. Staphylococcus aureus host specificity: comparative genomics of human versus animal isolates by multi-strain microarray. Microbiology. 2008;154:1949-59.

2. Smyth DS, Feil EJ, Meaney WJ, Hartigan PJ, Tollersrud T, Fitzgerald JR, et al. Molecular genetic typing reveals further insights into the diversity of animal-associated Staphylococcus aureus. J Med Microbiol. 2009:58:1343-53.

3. Wertheim HFL, Melles DC, Vos MC, Van Leeuwen W, Van Belkum A, Verbrugh HA, et al. Subscription Information: Review The role of nasal carriage in Staphylococcus aureus infections. Lancet Infect Dis. 2005;5:751-62.

4. Maina EK, Kiiyukia C, Wamae CN, Waiyaki PG, Kariuki S. Characterization of methicillin-resistant Staphylococcus aureus from skin and soft tissue infections in patients in Nairobi, Kenya. Int J Infect Dis. 2013;17:e115-9.

5. Ladhani S. Bacteraemia due to Staphylococcus aureus. Arch Dis Child. 2004. 89:568-71.

6. Fitzgerald JR. Livestock-associated Staphylococcus aureus: origin, evolution and public health threat. Trends Microbiol. 2012;20:192-8.

7. Guinane CM, Ben Zakour NL, Tormo-Mas MA, Weinert LA, Lowder BV, Cartwright RA, et al. Evolutionary genomics of Staphylococcus aureus reveals insights into the origin and molecular basis of ruminant host adaptation. Genome Biol Evol. 2010;2:454-66. 
8. Christou L. The global burden of bacterial and viral zoonotic infections. Clin Microbiol Infect. 2011;17:326-30.

9. Petersen A, Stegger M, Heltberg O, Christensen J, Zeuthen A, Knudsen L, et al. Epidemiology of methicillin-resistant Staphylococcus aureus carrying the novel mecC gene in Denmark corroborates a zoonotic reservoir with transmission to humans. Clin Microbiol Infect. 2013:19:E16-22.

10. Abdurahman OAS. Udder health and milk quality among camels in the Errer valley of eastern Ethiopia. In: Livestock Research for Rural Development, vol. 18. 2006. p. 8.

11. Gautret P, Benkouiten S, Gaillard C, Parola P, Brouqui P. Camel milk-associated infection risk perception and knowledge in French Hajj pilgrims. Vector Borne Zoonotic Dis. 2013;13:425-7.

12. Sprague LD, Al-Dahouk S, Neubauer H. A review on camel brucellosis: a zoonosis sustained by ignorance and indifference. Pathog Glob Health. 2012;106:144-9.

13. Fischer A, Liljander A, Kaspar H, Muriuki C, Fuxelius H-H, Bongcam-Rudloff E, et al. Camel Streptococcus agalactiae populations are associated with specific disease complexes and acquired the tetracycline resistance gene tetM via a Tn916-like element. Vet Res. 2013;44:86.

14. Monecke S, Ehricht R, Slickers P, Wernery R, Johnson B, Jose S, et al. Microarray-based genotyping of Staphylococcus aureus isolates from camels. Vet Microbiol. 2011;150:309-14.

15. Younan $M$, Bornstein S. Papers \& Articles Lancefield group B and C streptococci in East African camels (Camelus dromedarius). Vet Rec. 2007; 160:330-5.

16. Younan M, Ali Z, Bornstein S, Müller W. Application of the California mastitis test in intramammary Streptococcus agalactiae and Staphylococcus aureus infections of camels (Camelus dromedarius) in Kenya. Prev Vet Med. 2001;51:307-16.

17. Wernery U, Kinne J, Schuster RK. Camelid Infectious Disorders. Paris, France: World Organisation for Animal Health OIE; 2014. p. 500

18. Carter GRCJ. Diagnostic procedures in veterinary bacteriology and mycology. 5th ed. San Diego, Calif: Academic; 1990. p. 620.

19. Hussain M, Von Eiff C, Sinha B, Joost I, Herrmann M, Peters G, et al. eap Gene as Novel Target for Specific Identification of Staphylococcus aureus. J Clin Microbiol. 2008:46:470-6.

20. Enright MC, Day NPJ, Davies CE, Peacock SJ. Multilocus sequence typing for characterization of methicillin- resistant and methicillin-susceptible clones of Staphylococcus aureus. J Clin Microbiol. 2000;38:1008-15.

21. Altschul SF, Gish W, Miller W, Myers EW, Lipmanl DJ. Basic Local Alignment Search Tool. J Mol Biol. 1990;215:403-10.

22. Chevreux B, Wetter T, Suhai S. Genome sequence assembly using trace signals and additional sequence information. In: Computer science and biology: proceedings of the German Conference on Bioinformatics, vol. 99. Göttingen, Germany: GCB; 1999. p. 45-56.

23. Darling AE, Mau B, Perna NT. Progressive Mauve: multiple genome alignment with gene gain, loss and rearrangement. PLoS One. 2010;5: e11147.

24. Kurtz S, Phillippy A, Delcher AL, Smoot M, Shumway M, Antonescu C, et al. Versatile and open software for comparing large genomes. Genome Biol. 2004:5:R12.

25. Holden MTG, Feil EJ, Lindsay JA, Peacock SJ, Day NPJ, Enright MC, et al. Complete genomes of two clinical Staphylococcus aureus strains: Evidence for the rapid evolution of virulence and drug resistance. Proc Natl Acad Sci U S A. 2004;101:9786-91.

26. Milne I, Stephen G, Bayer M, Cock PJA, Pritchard L, Cardle L, et al. Using Tablet for visual exploration of second-generation sequencing data. Brief Bioinform. 2013;14:193-202.

27. Aziz RK, Bartels D, Best AA, DeJongh M, Disz T, Edwards RA, et al. The RAST Server: rapid annotations using subsystems technology. BMC Genomics. 2008;9:75-89.

28. Lagesen $\mathrm{K}$, Hallin $\mathrm{P}$, Rødland EA, Staerfeldt H-H, Rognes T, Ussery DW. RNAmmer: consistent and rapid annotation of ribosomal RNA genes. Nucleic Acids Res. 2007:35:3100-8.

29. Lowe TM, Eddy SR. tRNAscan-SE: a program for improved detection of transfer RNA genes in genomic sequence. Nucl Acids Res. 1997;25:955-64

30. Tatusov RL, Galperin MY, Natale DA, Koonin EV. The COG database: a tool for genome-scale analysis of protein functions and evolution. Nucleic Acids Res. 2000;28:33-6.

31. BLAST+ executables. ftp://ftp.ncbi.nlm.nih.gov/blast/executables/blast+/.
32. Petersen TN, Brunak S, von Heijne G, Nielsen H. SignalP 4.0: discriminating signal peptides from transmembrane regions. Nat Methods. 2011;8:785-6.

33. Von Heijne G. Membrane hydrophobicity protein structure prediction analysis and the positive-inside. J Mol Biol. 1992;225:487-94

34. Zhou Y, Liang Y, Lynch KH, Dennis JJ, Wishart DS. PHAST: A Fast Phage Search Tool. Nucl Acids Res. 2011;39:W347-52.

35. NCBI FTP site. https://www.ncbi.n/m.nih.gov/Ftp/

36. McGavin MJ, Arsic B, Nickerson NN. Evolutionary blueprint for host- and niche-adaptation in Staphylococcus aureus clonal complex CC30. Front Cell Infect Microbiol. 2012;2:1-13.

37. Harro JM, Daugherty S, Bruno VM, Jabra-rizk MA, Rasko DA, Shirtliff E. Draft Genome Sequence of the Methicillin-Resistant Staphylococcus aureus Isolate MRSA-M2. Genome Announc. 2013;1:e00037-12.

38. Corrigan RM, Miajlovic H, Foster TJ. Surface proteins that promote adherence of Staphylococcus aureus to human desquamated nasal epithelial cells. BMC Microbiol. 2009:9:22

39. Clarke SR, Mohamed R, Bian L, Routh AF, Kokai-Kun JF, Mond JJ, et al. The Staphylococcus aureus surface protein IsdA mediates resistance to innate defenses of human skin. Cell Host Microbe. 2007;1:199-212.

40. Sinha B, Francois P, Que Y-A, Hussain M, Heilmann C, Moreillon P, et al. Heterologously expressed Staphylococcus aureus fibronectin-binding proteins are sufficient for invasion of host cells. Infect Immun. 2000;68:6871-8

41. Haggar A, Hussain M, Lo H, Herrmann M, Norrby-teglund A, Flock J. Extracellular Adherence Protein from Staphylococcus aureus Enhances Internalization into Eukaryotic Cells. Infect Immun. 2003;71:2310-7.

42. Burts ML, Williams WA, DeBord K, Missiakas DM. EsxA and EsxB are secreted by an ESAT-6-like system that is required for the pathogenesis of Staphylococcus aureus infections. Proc Natl Acad Sci U S A. 2005;102:1169-74.

43. Anderson M, Chen Y-H, Butler EK, Missiakas DM. EsaD, a secretion factor for the Ess pathway in Staphylococcus aureus. J Bacteriol. 2011;193:1583-9.

44. Ubeda C, Maiques E, Barry P, Matthews A, Tormo MA, Lasa I, et al. SaPI mutations affecting replication and transfer and enabling autonomous replication in the absence of helper phage. Mol Microbiol. 2008;67: 493-503.

45. Sato'o Y, Omoe K, Ono HK, Nakane A, Hu D-L. A novel comprehensive analysis method for Staphylococcus aureus pathogenicity islands. Microbiol Immunol. 2013;57:91-9.

46. Holtfreter $S$, Grumann D, Schmudde M, Nguyen HTT, Eichler $P$, Strommenger $\mathrm{B}$, et al. Clonal distribution of superantigen genes in clinical Staphylococcus aureus isolates. J Clin Microbiol. 2007:45:2669-80.

47. Angiuoli SV, Salzberg SL. Mugsy: fast multiple alignment of closely related whole genomes. Bioinformatics. 2011;27:334-42.

48. Guindon S, Gascuel O. A simple, fast, and accurate algorithm to estimate large phylogenies by maximum likelihood. Syst Biol. 2003;52:696-704.

49. Woese CR, Kandler O, Wheelis ML. Towards a natural system of organisms: Proposal for the domains Archaea, Bacteria, and Eucarya. Proc Natl Acad Sci U S A. 1990:87:4576-9.

50. Gibbons NE, Murray RGE. Proposals Concerning the Higher Taxa of Bacteria. Int J Syst Bacteriol 1978:1:1-6

51. Schleifer K-H. Phylum XIII. Firmicutes. In: De Vos P, Garrity G, Jones D, Krieg NR, Ludwig W, Rainey FA, Schleifer KH WW, editors. Bergey's Manual of Systematic Bacteriology, Second Edition, Volume 3. New York: Springer; 2009. p. 19.

52. Ludwig W, Schleifer K-H, Whitman WB. Class I. Bacilli class nov. In: De Vos P, Garrity G, Jones D, Krieg NR, Ludwig W, Rainey FA, Schleifer KH WW, editors. Bergey's Manual of Systematic Bacteriology, Second Edition, Volume 3. Springer-Verlag, New York; 2009. p. 19-20

53. Anon. List of new names and new combinations previously effectively, but not validly, published. List no. 132. Int J Syst Evol Microbiol. 2010;60:469-72.

54. De Vos P. Order I. Bacillales Prévot 1953, 60AL. In: De Vos P, Garrity G, Jones D, Krieg NR, Ludwig W, Rainey FA, Schleifer KH WW, editors. Bergey's Manual of Systematic Bacteriology, Second Edition, Volume 3. Springer-Verlag, New York; 2009. p. 20.

55. Yakoubou S, Xu D, Côté J. Phylogeny of the Order Bacillales inferred from 3' $16 S$ rDNA and 5' 16S-23S ITS nucleotide sequences. Nat Sci. 2010:2:990-7.

56. Skerman VBD, McGowan V, Sneath PHA. Approved lists of bacterial names. Int J Syst Bacteriol. 1980;30:225-420.

57. Prévot AR. Dictionnaire des Bactéries Pathogènes. 2nd ed. In: Hauderoy $P$, Ehringer G, Guillot G, J. M, Prévot AR, Rosset D, Urbain A, editors. Paris: Masson et Cie; 1953. p. 1-692. 
58. Schleifer K-H, Bell JA. Family VIII. Staphylococcaceae fam. nov. In: De Vos P, Garrity G, Jones D, Krieg NR, Ludwig W, Rainey FA, Schleifer KH WW, editors. Bergey's Manual of Systematic Bacteriology, Second Edition, Volume 3. Springer-Verlag, New York; 2009. p. 392.

59. Ashburner M, Ball CA, Blake JA, Botstein D, Butler H, Cherry JM, et al. Gene Ontology: tool for the unification of biologybiology. The Gene Ontology Consortium. Nat Genet. 2000;25:25-9.

60. Tamura K, Stecher G, Peterson D, Filipski A, Kumar S. MEGA6: Molecular Evolutionary Genetics Analysis version 6.0. Mol Biol Evol. 2013;30:2725-9.

61. Carver T, Thomson N, Bleasby A, Berriman M, Parkhill J. DNAPlotter: circular and linear interactive genome visualization. Bioinformatics. 2009;25:119-20.

62. Gene Ontology Consortium. Gene ontology consortium: going forward. Nucleic acids research 43, no. D1 (2015): D1049-D1056. http://www. geneontology.org

63. Tamura, Koichiro, Glen Stecher, Daniel Peterson, Alan Filipski, Sudhir Kumar. "MEGA6: molecular evolutionary genetics analysis version 6.0."Molecular biology and evolution 30, no. 12 (2013): 2725-729.

64. Carver, Tim, Nick Thomson, Alan Bleasby, Matthew Berriman, and Julian Parkhill. "DNAPlotter: circular and linear interactive genome visualization. "Bioinformatics 25, no. 1 (2009): 119-20.

\section{Submit your next manuscript to BioMed Central and take full advantage of:}

- Convenient online submission

- Thorough peer review

- No space constraints or color figure charges

- Immediate publication on acceptance

- Inclusion in PubMed, CAS, Scopus and Google Scholar

- Research which is freely available for redistribution 